\title{
Effects of Smoking and HLA-B51 on Clinical Manifestations in Behçet's Disease: Retrospective Analysis of 209 Patients in a Turkish Population
}

\author{
Serpil TUNA, ${ }^{1}$ Sevil ALAN, ${ }^{2}$ Elif Betül TÜRKOĞLU ${ }^{3}$ \\ ${ }^{1}$ Department of Physical Medicine and Rehabilitation, Medical Faculty of Akdeniz University, Antalya, Turkey \\ ${ }^{2}$ Department of Dermatology, Medical Faculty of Akdeniz University, Antalya, Turkey \\ ${ }^{3}$ Department of Oftalmology, Medical Faculty of Akdeniz University, Antalya, Turkey
}

\begin{abstract}
Objectives: This study aims to investigate the separate and cumulative effects of smoking and human leukocyte antigen (HLA)-B51 on the severity and clinical manifestations of Behçet's disease (BD).

Patients and methods: A total of 209 patients (119 males, 90 females; mean age $42.97 \pm 10.44$ years; range 23 to 75 years) with BD were included in this retrospective study. The severity and clinical manifestations of BD, smoking habits, and presence of HLA-B51 of patients were obtained from medical records. The severity of BD was evaluated with Behçet's Syndrome Activity Scale (BSAS). Relationship between smoking habits and presence of HLA-B51 with disease severity and clinical manifestations was investigated.

Results: Presence of HLA-B51 was effective on BSAS, erythema nodosum (EN), articular, ocular and neurological involvements $(p=0.001$, $p=0.011$, $p=0.013, p=0.001, p=0.038$, respectively). Smoking was also effective on BSAS, EN, articular, ocular and neurological involvements $(p=0.001, p=0.001$, $p=0.013, p=0.042, p=0.027$, respectively). There was a strong association between positive HLA-B51 with smoking ( $p=0.004)$. Smoking and HLAB51 were effective on articular involvement, smoking was effective on EN, and HLA-B51 and smoking were effective on ocular and neurological involvements ( $p=0.039, p=0.040, p=0.001, p=0.028, p=0.037$, respectively).

Conclusion: Our findings indicate that smoking and HLA-B51 influence severity and systemic involvements of BD with a positive relationship in between. We recommend that smoking and HLA-B51 should be considered simultaneously in BD since this relationship may lead to incorrect inferences.

Keywords: Behçet's disease; human leukocyte antigen-B51; smoking.
\end{abstract}

Behçet's disease (BD) is an autoimmune inflammatory disorder characterized by recurrent oral aphthous ulcers, genital ulcers, and the involvement of musculoskeletal and other systems. Clinical features of $\mathrm{BD}$ are affected by both genetic and environmental factors and may vary between individuals and societies. ${ }^{1,2}$

Human leukocyte antigen (HLA)-B51 has been recognized as the strongest genetic predisposing factor for $\mathrm{BD}$. In the literature, a relationship has been reported between HLA-B51 and different manifestations of $\mathrm{BD}$ which varies according to regions and ethnic backgrounds., ${ }^{1,3,4}$

Smoking which is the most widespread addiction in the world is an environmental factor associated with many diseases. Toxic components in the cigarette which stimulate vasospasm and platelet aggregation while decreasing the antioxidants in blood damage the vascular and immune systems. ${ }^{2}$ There are different speculations about the relationship between $\mathrm{BD}$ and smoking. While some authors claim that 
smoking can activate, others claim that smoking cessation can activate several manifestations of $\mathrm{BD}$. However; the general consensus is that smoking alleviates oral aphthous lesions but aggravates other manifestations of BD. ${ }^{5-8}$

In the literature, there are studies which investigated the effect of HLA-B51 or smoking on the manifestations of $\mathrm{BD}$. However, to our knowledge, there is no other study that investigated the cumulative effects of both on the clinical manifestations of $\mathrm{BD}$. Therefore, in this study, we aimed to investigate the separate and cumulative effects of smoking and HLA-B51 on the severity and clinical manifestations of $\mathrm{BD}$.

\section{PATIENTS AND METHODS}

We retrospectively reviewed the medical records of 209 patients with BD (119 males, 90 females; mean age $42.97 \pm 10.44$ years; range 23 to 75 years) who were examined in Physical Medicine and Rehabilitation, Dermatology and Ophthalmology Department of Medical Faculty of Akdeniz University between January 2010 and October 2014. Patients older than 18 years of age and who met the 1990 International Study Group classification criteria for BD were included. ${ }^{9}$ Patients who had other inflammatory diseases such as rheumatic diseases, infectious diseases (hepatitis B virus, hepatitis C virus, human immunodeficiency virus), and malignancy were excluded. Informed consents were obtained from patients in accordance with the Declaration of Helsinki.

All patients were evaluated for their smoking status and separated into a smoking group (smoking or smoking cessation patients, $\mathrm{n}=103$ ) and non-smoking group (never smoking patients, $n=106)$. Patients were also classified as HLA-B51 positive $(n=62)$ or negative $(n=147)$. In the last stage, patients were divided into four groups: Group 0 (HLA-B51 negative and non-smoking), Group 1 (HLA-B51 positive and non-smoking), Group 2 (HLA-B51 negative and smoking), and Group 3 (HLA-B51 positive and smoking).

Behçet's Syndrome Activity Scale (BSAS) ${ }^{10}$ scores were noted for all patients. The manifestations of $\mathrm{BD}$ and articular- extra-articular involvements were noted. Patients with articular involvement were classified as monoarticular, oligoarticular, and polyarticular.

\section{Statistical analysis}

The IBM SPSS version 20.0 software program (IBM Corporation, Armonk, NY, USA) was used for statistical analysis. Chi-square tests were used for comparing nominal variables. Shapiro-Wilk test was used for testing normality. Multivariate analysis was performed using binary logistic regression with forward conditional method. Four groups were compared using KruskalWallis test, later the groups were compared with each other using Mann-Whitney U test and Bonferroni correction. Alpha significance level less than 0.05 was considered as statistically significant.

\section{RESULTS}

The demographic and clinical characteristics of patients are summarized in Table 1. Smoking rate was significantly higher in male sex than female sex. Demographic and clinical characteristics of patients with BD according to sex are summarized in Table 2 .

A comparison of demographic and clinical characteristics of HLA-B51 positive and -negative patients with $\mathrm{BD}$ revealed that rate of smokers, BSAS scores, EN, articular, ocular and neurological involvements were significantly higher in HLAB51 positive patients than HLA-B51 negative patients $(p<0.05)$ (Table 3$)$.

A comparison of demographic and clinical characteristics of smoking group and nonsmoking group with $\mathrm{BD}$ showed that male sex, HLA-B51 positive patients, BSAS scores, EN, articular, ocular and neurological involvements were significantly higher in smoking group than non-smoking group $(\mathrm{p}<0.05)$ (Table 4$)$.

An investigation of the effect of consumed cigarette amount on articular and extra-articular involvement in $\mathrm{BD}$ demonstrated that the smoking pack/years did not affect articular, ocular or neurological involvement, or EN $(p=0.434$, $p=0.371, p=0.476, p=0.839$, respectively). Also, there was no correlation between these and BSAS scores. 


\begin{tabular}{|c|c|c|c|c|}
\hline & $\mathrm{n}$ & $\%$ & Mean \pm SD & Min.-Max. \\
\hline Age (years) & & & $42.97 \pm 10.44$ & $23-75$ \\
\hline Disease duration (years) & & & $8.46 \pm 6.05$ & $1-36$ \\
\hline \multicolumn{5}{|l|}{ Gender } \\
\hline Female & 90 & 43.1 & & \\
\hline Male & 119 & 56.9 & & \\
\hline \multicolumn{5}{|l|}{ Smoking } \\
\hline \multicolumn{5}{|l|}{+} \\
\hline Current & 65 & 31.1 & & \\
\hline Cessation & 38 & 18.2 & & \\
\hline Total smokers & 103 & 49.3 & & \\
\hline Tobacco per day & & & $16.02 \pm 7.587$ & $2-50$ \\
\hline Duration (years) & & & $12.88 \pm 8.21$ & $2-40$ \\
\hline Pack (years) & & & $11.01 \pm 9.62$ & $0.20-40$ \\
\hline \multicolumn{5}{|l|}{-} \\
\hline Non-smokers & 106 & 50.7 & & \\
\hline Human leukocyte antigen-B51 (+) & 62 & 29.7 & & \\
\hline Behçet's Syndrome Activity Scale scores & & & $5.34 \pm 2.05$ & $2-14$ \\
\hline \multicolumn{5}{|l|}{ Articular involvement } \\
\hline Monoarticular & 78 & 37.3 & & \\
\hline Oligoarticular & 46 & 22.0 & & \\
\hline Poliarticular & 15 & 7.2 & & \\
\hline Total & 139 & 66.5 & & \\
\hline \multicolumn{5}{|l|}{ Extra-articular involvement } \\
\hline \multicolumn{5}{|l|}{ Mucocutaneous } \\
\hline Oral ulcer & 205 & 100 & & \\
\hline Genital ulcer & 190 & 90.9 & & \\
\hline Papulopustular lesions & 153 & 73.2 & & \\
\hline Erythema nodosum & 90 & 43.1 & & \\
\hline Gastrointestinal system & 5 & 2.4 & & \\
\hline Cardiovascular system & 35 & 16.75 & & \\
\hline Ocular & 73 & 34.93 & & \\
\hline Neurological & 8 & 38.3 & & \\
\hline
\end{tabular}

Three binary logistic regression models were performed to analyze factors affecting articular, ocular involvements, and EN. Both smoking and HLA-B51 were effective on articular involvement. Smoking was effective on EN. While smoking or HLA alone was not effective, HLA-B51 with smoking was effective on ocular and neurological involvements (Table 5).
When four groups were compared to investigate the effects of smoking and/or HLA-B51 on BSAS scores, a significant difference was shown. The BSAS scores of group 1 and 2 were significantly higher than in group 0 and the BSAS scores of group 3 were significantly higher than in group 0,1 and 2; however, there was no significant difference between groups 1 and 2 . Both smoking

Table 2. Demographic and clinical characteristics of patients with Behçet's disease according to sex

\begin{tabular}{|c|c|c|c|c|c|c|c|}
\hline & \multicolumn{3}{|c|}{ Female } & \multicolumn{3}{|c|}{ Male } & \multirow[b]{2}{*}{$p$} \\
\hline & $\mathrm{n}$ & $\%$ & Mean \pm SD & $\mathrm{n}$ & $\%$ & Mean \pm SD & \\
\hline Gender & 90 & 100 & & 119 & 100 & & \\
\hline Human leukocyte antigen-B51 (+) & 24 & 26.7 & & 38 & 31.9 & & 0.409 \\
\hline Smoking & 36 & 56.3 & & 67 & 40.0 & & $0.020^{*}$ \\
\hline Articular involvement & 66 & 73.3 & & 73 & 61.3 & & 0.069 \\
\hline Erythema nodosum & 44 & 48.9 & & 46 & 38.7 & & 0.139 \\
\hline Ocular involvement & 29 & 32.2 & & 44 & 37.0 & & 0.475 \\
\hline Neurological involvement & 2 & 2.2 & & 6 & 5.0 & & NA \\
\hline Behçet's Syndrome Activity Scale & & & $5.01 \pm 1.95$ & & & $5.59 \pm 2.10$ & $0.028^{*}$ \\
\hline
\end{tabular}


Table 3. Demographic and clinical characteristics of human leukocyte antigen-B51-positive and -negative patients with Behçet's disease $(n=209)$

\begin{tabular}{|c|c|c|c|c|c|c|c|}
\hline & \multicolumn{3}{|c|}{ HLA-B51 (+) $(\mathrm{n}=62)$} & \multicolumn{3}{|c|}{ HLA-B51 (-) $(\mathrm{n}=147)$} & \multirow[b]{2}{*}{$p$} \\
\hline & $\mathrm{n}$ & $\%$ & Mean \pm SD & $\mathrm{n}$ & $\%$ & Mean \pm SD & \\
\hline \multicolumn{8}{|l|}{ Gender } \\
\hline Male & 38 & 61.3 & & 81 & 55.1 & & \\
\hline Female & 24 & 38.7 & & 66 & 44.9 & & 0.400 \\
\hline Smoking & 40 & 64.5 & & 63 & 42.9 & & $0.004^{*}$ \\
\hline Behçet's Syndrome Activity Scale scores & & & $6.61 \pm 2.145$ & & & $4.80 \pm 1.762$ & $0.001^{*}$ \\
\hline \multicolumn{8}{|l|}{ Articular involvement } \\
\hline Monoarticular & 20 & 32.3 & & 58 & 39.5 & & \\
\hline Oligoarticular & 20 & 32.3 & & 26 & 17.7 & & \\
\hline Poliarticular & 9 & 14.5 & & 6 & 4.1 & & $0.001^{*}$ \\
\hline Total & 49 & 79.0 & & 90 & 61.2 & & $0.013^{*}$ \\
\hline \multicolumn{8}{|l|}{ Extra-articular involvement } \\
\hline \multicolumn{8}{|l|}{ Mucocutaneous } \\
\hline Genital ulcer & 53 & 85.5 & & 137 & 93.2 & & 0.076 \\
\hline Papulopustular lesions & 49 & 79.0 & & 104 & 70.7 & & 0.217 \\
\hline Erythema nodosum & 35 & 56.6 & & 55 & 37.4 & & $0.011^{*}$ \\
\hline Gastrointestinal system & 3 & 4.8 & & 2 & 1.4 & & NA \\
\hline Cardiovascular system & 14 & 22.6 & & 21 & 14.3 & & 0.142 \\
\hline Ocular & 35 & 56.5 & & 38 & 25.9 & & $0.001^{*}$ \\
\hline Neurological & 5 & 8.1 & & 3 & 2.0 & & $0.038^{*}$ \\
\hline
\end{tabular}

and HLA-B51 were effective on BSAS scores, but HLA-B51 with smoking was significantly more effective on BSAS scores (Table 6).

\section{DISCUSSION}

In this study, both smoking and positive HLAB51 were found to be effective on BSAS, EN, articular, ocular and neurological involvements. Surprisingly, smoking rate was higher in the patients with positive HLA-B51 than in patients with negative HLA-B51.

In the literature, many studies have shown that HLA-B51 and smoking are factors associated with clinical manifestations of $\mathrm{BD} .^{2,5,7,11}$ Gür et al. ${ }^{12}$ have reported that HLA-B51 rate

Table 4. Demographic and clinical characteristics of smoking and non-smoking patients with Behçet's disease $(n=209)$

\begin{tabular}{|c|c|c|c|c|c|c|c|}
\hline & \multicolumn{3}{|c|}{ Smoking $(\mathrm{n}=103)$} & \multicolumn{3}{|c|}{ Non-smoking $(\mathrm{n}=106)$} & \multirow[b]{2}{*}{$p$} \\
\hline & $\mathrm{n}$ & $\%$ & Mean \pm SD & $\mathrm{n}$ & $\%$ & Mean \pm SD & \\
\hline \multicolumn{8}{|l|}{ Gender } \\
\hline Male & 67 & 65.0 & & 52 & 49.1 & & \\
\hline Female & 36 & 35.0 & & 54 & 50.9 & & $0.020^{*}$ \\
\hline Human leukocyte antigen-B51 (+) & 40 & 38.8 & & 22 & 20.8 & & $0.004^{*}$ \\
\hline Behçet's Syndrome Activity Scale Scores & & & $6.23 \pm 2.07$ & & & $4.47 \pm 1.63$ & $0.001^{*}$ \\
\hline \multicolumn{8}{|l|}{ Articular involvement } \\
\hline Monoarticular & 37 & 35.9 & & 41 & 38.7 & & \\
\hline Oligoarticular & 31 & 30.1 & & 15 & 14.2 & & \\
\hline Poliarticular & 9 & 8.7 & & 6 & 5.7 & & $0.012^{*}$ \\
\hline Total & 77 & 74.7 & & 62 & 58.5 & & $0.013 *$ \\
\hline \multirow{2}{*}{\multicolumn{8}{|c|}{$\begin{array}{l}\text { Extra-articular involvement } \\
\text { Mucocutaneous }\end{array}$}} \\
\hline Mucocutaneous & & & & & & & \\
\hline Genital ulcer & 91 & 88.3 & & 99 & 93.4 & & 0.205 \\
\hline Papulopustular lesions & 72 & 69.0 & & 81 & 76.4 & & 0.288 \\
\hline Erythema nodosum & 60 & 58.3 & & 30 & 28.3 & & $0.001^{*}$ \\
\hline Gastrointestinal system & 3 & 2.9 & & 2 & 2.9 & & NA \\
\hline Cardiovascular system & 18 & 17.5 & & 17 & 16.0 & & 0.781 \\
\hline Ocular & 43 & 41.7 & & 30 & 28.3 & & $0.042 *$ \\
\hline Neurological & 7 & 6.8 & & 1 & 0.9 & & $0.027^{*}$ \\
\hline
\end{tabular}




\begin{tabular}{|c|c|c|c|c|c|}
\hline & Predictors & Outcome & $p$ & $\operatorname{Exp}(B)$ & $95 \% \mathrm{CI}$ \\
\hline Model 1 & $\begin{array}{l}\text { Smoking } \\
\text { HLA-B51 (+) } \\
\text { HLA-B51 (+) and smoking }\end{array}$ & Articular & $\begin{array}{l}0.039^{*} \\
0.040^{*} \\
0.405\end{array}$ & $\begin{array}{l}2.11 \\
1.88\end{array}$ & $\begin{array}{l}1.04-4.30 \\
1.03-3.43\end{array}$ \\
\hline Model 2 & $\begin{array}{l}\text { Smoking } \\
\text { HLA-B51 (+) } \\
\text { HLA-B51 (+) and smoking }\end{array}$ & Erythema nodosum & $\begin{array}{l}0.001^{*} \\
0.076 \\
0.129\end{array}$ & 3.54 & $1.99-6.29$ \\
\hline Model 3 & $\begin{array}{l}\text { Smoking } \\
\text { HLA-B51 (+) } \\
\text { HLA-B51 (+) and smoking* }\end{array}$ & Ocular & $\begin{array}{l}0.153 \\
0.266 \\
0.028^{*}\end{array}$ & 2.19 & $1.09-4.41$ \\
\hline
\end{tabular}

in Behçet's patients with articular involvement was significantly higher than patients without articular involvement, but smoking rates were not significantly different among them. In our study, both HLA-B51 and smoking were shown to be effective, but both of them when they are together were not more influential on articular involvement.

In the literature, an association between HLA-B51 with clinical involvement and prognosis of $\mathrm{BD}$ has been reported. ${ }^{13-16}$ Results of these studies partially support our findings, but they have not examined whether patients smoke or not. Bilgin et al. ${ }^{2}$ have also reported that cystoid macular edema among current smoking patients with BD was significantly higher than nonsmoking patients, but smoking was inefficient on other ocular involvement. They have not examined HLA-B51. Their finding might seem to be partially different at first glance from our finding; however, they have accepted their patients who quit smoking in the not smoking category. Hirohata ${ }^{17}$ reported that positive HLAB51 rate was higher in patients with neurological involvement than patients without neurological involvement in BD.

According to our results, smoking is a risk factor for ocular and neurological involvements in patients with positive HLA-B51. Therefore, we may recommend that both HLA and smoking habits should be evaluated in patients with $\mathrm{BD}$ as well as studies on clinical findings of BD.

Another relationship referred to in the literature is between poor prognosis and severe complications of $\mathrm{BD}$ with male sex. ${ }^{18}$ The results of some studies have shown that systemic involvements, disease severity and poor prognosis of $\mathrm{BD}$ were associated with male sex..$^{19,20}$ Moreover, Hirohata ${ }^{17}$ has affirmed that HLA-B51, smoking, and male sex is strongly associated with chronic progressive $\mathrm{BD}$ with neurological involvement.

\begin{tabular}{|c|c|c|c|c|c|}
\hline & $\mathrm{n}$ & Median & 25-50 percentile & $p$ & Test \\
\hline Group 0 & 84 & 4.0 & $3.0-5.0$ & $0.001^{*}$ & \\
\hline Group 1 & 22 & 5.5 & $3.75-7.0$ & & \\
\hline Group 2 & 63 & 5.0 & $4.0-7.0$ & & \\
\hline Group 3 & 40 & 7.0 & $6.0-8.0$ & & Kruskal-Wallis \\
\hline Group 0-1 & & & $0.004^{*}$ & & \\
\hline Group 0-2 & & & $0.001^{*}$ & & \\
\hline Group 0-3 & & & $0.001^{*}$ & & \\
\hline Group 1-2 & & & 0.788 & & \\
\hline Group 1-3 & & & $0.004^{*}$ & & \\
\hline Group 2-3 & & & $0.001^{*}$ & & Mann-Whitney U \\
\hline
\end{tabular}


Male sex was not associated with BD manifestation in our study. Also, there was no significant difference between males and females in terms of HLA-B51. In studies associating systemic involvements and disease severity of $\mathrm{BD}$ with male sex, HLA-B51 frequency was generally higher in males than females. Besides, when taking into account that males generally smoke more than females, as in our study, this relationship may be due to direct smoking and/or indirect positive HLA-B51.

In their meta-analysis, Maldini et al. ${ }^{21}$ have reported that HLA-B51 was significantly associated with male sex, and ocular and skin involvements including $\mathrm{EN}$. In our study, EN seems to be associated with both HLA-B51 and smoking, but the influence factor was smoking on EN. The increased EN in patients with positive HLA-B51 may be due to the association of positive HLA-B51 with smoking. Also, the relationship between male sex with positive HLA-B51 and smoking may indicate that males smoke more because they have higher HLA-B51 frequency than females.

A relationship between smoking and severity of $\mathrm{BD}$ has been shown in the literature. ${ }^{22}$ However, there are conflicting results about the relationship between HLA-B51 and smoking with severity of BD. ${ }^{23-25}$ In our study, both smoking and HLA-B51 were found to be effective on $\mathrm{BD}$. In addition, their concurrent presence was demonstrated to be more effective on $\mathrm{BD}$ activity scores.

The limitation of this study is that there was no control group. There is need for further studies in this regard.

In conclusion, we may say that smoking and HLA-B51 are influential factors on severity and systemic involvements of $\mathrm{BD}$ and there is a positive relationship between them. This relationship affects severity and same clinical manifestations of $\mathrm{BD}$, sometimes leading to incorrect inferences. Therefore, we recommend that smoking and HLA-B51 should be considered simultaneously in BD with clarifications by further studies.

\section{Acknowledgements}

The authors are greatly indebted to Mehmet İhsan Arman and Kemal Hakan Gülkesen for his help during preparation of this work.

\section{Declaration of conflicting interests}

The authors declared no conflicts of interest with respect to the authorship and/or publication of this article.

\section{Funding}

The authors received no financial support for the research and/or authorship of this article.

\section{REFERENCES}

1. Paovic J, Paovic P, Sredovic V. Behcet's disease: systemic and ocular manifestations. Biomed Res Int 2013;2013:247345.

2. Bilgin AB, Turkoglu EB, Ilhan HD, Unal M, Apaydin KC. Is Smoking a Risk Factor in Ocular Behçet Disease? Ocul Immunol Inflamm 2014 Apr 15. [Epub ahead of print]

3. Shadmanfar S, Shahram F, Nadji A, Akhlaghi M, Faezi ST, Sadeghi-Abdollahi B, et al. The relationship between plasma homocysteine level and HLA-B51 in patients with Behcet's disease: a case-control study. Int $J$ Rheum Dis 2014;17:466-70.

4. Sano K, Yabuki K, Imagawa Y, Shiina T, Mizuki $\mathrm{N}$, Ohno $\mathrm{S}$, et al. The absence of disease-specific polymorphisms within the HLA-B51 gene that is the susceptible locus for Behçet's disease. Tissue Antigens 2001;58:77-82.

5. Özer HT, Günesaçar R, Dinkçi S, Özbalkan Z, Yildiz F, Erken E. The impact of smoking on clinical features of Behçet's disease patients with glutathione S-transferase polymorphisms. Clin Exp Rheumatol 2012;30(3 Suppl 72):S14-7.

6. Kalayciyan A, Orawa H, Fimmel S, Perschel FH, González JB, Fitzner RG, et al. Nicotine and biochanin $\mathrm{A}$, but not cigarette smoke, induce anti-inflammatory effects on keratinocytes and endothelial cells in patients with Behçet's disease. J Invest Dermatol 2007;127:81-9.

7. Soy M, Erken E, Konca K, Ozbek S. Smoking and Behçet's disease. Clin Rheumatol 2000;19:508-9.

8. Rizvi SW, McGrath H Jr. The therapeutic effect of cigarette smoking on oral/genital aphthosis and other manifestations of Behçet's disease. Clin Exp Rheumatol 2001;19(5 Suppl 24):S77-8.

9. Criteria for diagnosis of Behçet's disease. International Study Group for Behçet's Disease. Lancet 1990;335:1078-80.

10. Yilmaz S, Simsek I, Cinar M, Erdem H, Kose $\mathrm{O}$, Yazici $\mathrm{Y}$, et al. Patient-driven assessment of disease activity in Behçet's syndrome: cross-cultural adaptation, reliability and validity of the Turkish version of the Behçet's Syndrome Activity Score. Clin Exp Rheumatol 2013;31(3 Suppl 77):77-83.

11. Wallace GR. HLA-B*51 the primary risk in Behçet disease. Proc Natl Acad Sci U S A. 2014;111:8706-7.

12. Gur A, Sarac AJ, Burkan YK, Nas K, Cevik R. Arthropathy, quality of life, depression, and anxiety 
in Behcet's disease: relationship between arthritis and these factors. Clin Rheumatol 2006;25:524-31.

13. Krause L, Köhler AK, Altenburg A, Papoutsis N, Zouboulis CC, Pleyer U, et al. Ocular involvement is associated with HLA-B51 in Adamantiades-Behçet's disease. Eye (Lond) 2009;23:1182-6.

14. Noel N, Bernard R, Wechsler B, Resche-Rigon M, Depaz R, Le Thi Huong Boutin D, et al. Longterm outcome of neuro-Behçet's disease. Arthritis Rheumatol 2014;66:1306-14.

15. Shahram F, Davatchi F, Nadji A, Jamshidi A, Bahar $\mathrm{K}$, Akbarian M, et al. Association of HLA-B51 with clinical expression of Behçet's disease. Analysis of 201 Iranian patients. Adv Exp Med Biol 2003;528:147-8.

16. Tanaka T, Momi H, Horinouti S, Kawabata S, Umehara F. A case of neuro-Behcet's disease with transient cerebral ischemia evoked by smoking. Rinsho Shinkeigaku 1999;39:546-50. [Abstract]

17. Hirohata S. Recent aspects of Neuro-Behcet's disease. Brain Nerve 2013;65:1245-53. [Abstract]

18. Direskeneli H. Behçet's disease: infectious aetiology, new autoantigens, and HLA-B51. Ann Rheum Dis 2001;60:996-1002.

19. Balta I, Akbay G, Kalkan G, Eksioglu M. Demographic and clinical features of 521 Turkish patients with Behçet's disease. Int J Dermatol 2014;53:564-9.
20. Houman MH, Bellakhal S, Ben Salem T, Hamzaoui A, Braham A, Lamloum M, et al. Characteristics of neurological manifestations of Behçet's disease: a retrospective monocentric study in Tunisia. Clin Neurol Neurosurg 2013;115:2015-8.

21. Maldini C, Lavalley MP, Cheminant M, de Menthon M, Mahr A. Relationships of HLA-B51 or B5 genotype with Behcet's disease clinical characteristics: systematic review and meta-analyses of observational studies. Rheumatology (Oxford) 2012;51:887-900.

22. Aramaki K, Kikuchi H, Hirohata S. HLA-B51 and cigarette smoking as risk factors for chronic progressive neurological manifestations in Behçet's disease. Mod Rheumatol 2007;17:81-2.

23. Hamzaoui A, Houman MH, Massouadia M, Ben Salem T, Khanfir MS, Ben Ghorbel I, et al. Contribution of Hla-B51 in the susceptibility and specific clinical features of Behcet's disease in Tunisian patients. Eur J Intern Med 2012;23:347-9.

24. Gül A, Uyar FA, Inanc M, Ocal L, Tugal-Tutkun I, Aral O, et al. Lack of association of HLA-B*51 with a severe disease course in Behçet's disease. Rheumatology (Oxford) 2001;40:668-72.

25. Krause I, Molad Y, Weinberger A. Association of HLAB5 with Clinical Expression and Severity of Behcet's Disease in Israel. J Clin Rheumatol 1999;5:137-40. 